\title{
The current status of occupational health in China
}

\author{
Xueyan Zhang $\cdot$ Zhongxu Wang $\cdot$ Tao Li
}

Received: 19 January 2010/ Accepted: 31 March 2010/Published online: 1 June 2010

(C) The Japanese Society for Hygiene 2010

\begin{abstract}
Objective This study aimed to summarize the major health problems among Chinese workers, the strategies and measures for occupational hazards control, the network and organizations of occupational health administration, and the achievements and current challenges of occupational health in China.

Results The situation of occupational health was found to be still serious in China. Enterprises with occupational hazards were widely distributed, the exposed population and cases of occupational diseases were numerous, and occupational risks were being transferred from the city to the countryside and from developed areas to developing ones. New emerging problems coexisted with traditional occupational hazards. Besides, a lack of occupational health services for migrant workers could be a major problem for a long time.

Conclusions It is necessary to improve the fields related to occupational health, such as the supervision and administration of small- and medium-scale enterprises, research into key techniques for the prevention and control of occupational hazards, systems for the diagnosis and reporting of occupational diseases, and the training of health professionals.
\end{abstract}

Keywords Occupational health · China . Occupational disease - Protection · BOHS

X. Zhang · Z. Wang $(\bowtie) \cdot$ T. Li

National Institute of Occupational Health and Poison Control, Chinese Center for Disease Control and Prevention,

Nanwei Road 29th, Xuanwu District,

Beijing 100050, China

e-mail: wangzhongxu2003@163.com

$\begin{array}{ll}\text { Abbreviations } \\ \text { ILO } & \text { International Labor Organization } \\ \text { GDP } & \text { Gross domestic product } \\ \text { PRC } & \text { People's Republic of China } \\ \text { TNT } & \text { Trinitrotoluene } \\ \text { LBP } & \text { Low back pain } \\ \text { MSDs } & \text { Musculoskeletal disorders } \\ \text { OACD } & \text { Occupational allergic contact dermatitis } \\ \text { GBZ } & \text { Mandatory national standards } \\ \text { GBZ/T } & \text { Recommended national standards } \\ \text { FEV1 } & \text { Forced expiratory volume in the first second } \\ \text { CDC } & \text { Center for disease control and prevention } \\ \text { BOHS } & \text { Basic occupational health services } \\ \text { WHO } & \text { World Health Organization } \\ \text { ICOH } & \text { International Commission on Occupational } \\ & \text { Health } \\ \text { IHI } & \text { Institute of Health Inspection } \\ \text { IOHPC } & \text { Institute of Occupational Health and } \\ & \text { Poisoning Control } \\ \text { CCDC } & \text { Chinese Center for Disease Control and } \\ \text { OHIs } & \text { Prevention } \\ \text { NCODPT } & \text { Occupational health institutions } \\ & \text { Prevention and Treatment }\end{array}$

\section{Introduction}

With the dramatic economic development over the past 20 years, China has faced the coexistence of new emerging problems and traditional occupational hazards in a short period. By the end of 2001, the Chinese economically active population reached 730.25 million [1]. Among them, a large proportion was potentially exposed to occupational 
hazards. Those who worked in small- and medium-scale enterprises were at most risk. The International Labor Organization (ILO) estimated that China's 2001 workplace fatality rate was 11.1 per 100,000 workers. By the end of 2008, 704,602 cases of occupational disease had been reported all over the country [2]. In addition, new occupational problems such as the occupational health of migrant workers, the transferring of occupational hazards, new occupational hazards, and work-related diseases were also great challenges. The current status of China's occupational health is introduced briefly in this article.

The major occupational health problems in China

A high incidence of occupational disease was found to be one of the main health problems. The well known hazards, such as silica and asbestos, were still affecting the workers in this country. These hazards were faced decades ago by millions of workers. Figure 1 shows the incidence of occupational diseases in China in the 11-year period until 2007.

\section{Pneumoconiosis}

In China, the number of workers exposed to silicacontaining dusts was estimated to be as high as 12 million [3]. Pneumoconiosis has been the most serious and preventable occupational disease for a long time. In recent years, new cases were estimated at 12,000-15,000 annually, representing $70-80 \%$ of the total number of cases of reported occupational diseases. The cumulative number of confirmed pneumoconiosis cases recorded in China between 1949 and 2008 reached 638,234. Most of the cases were found in coal-mining industries, followed by the construction materials manufacturing industry, the metallurgical industry, non-ferrous metal industries, and machinery industries [3]. The direct costs of the diagnosis and treatment

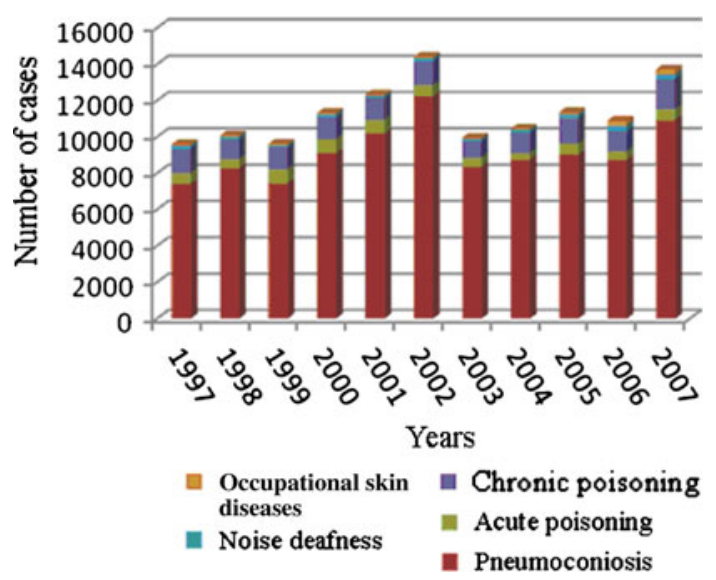

Fig. 1 Incidence of occupational diseases in a recent 10 -year period in China of pneumoconiosis were more than CNY12,000 (USD1758) for one patient per year. This was just one-tenth of the indirect cost. According to this ratio, the direct and indirect costs of one million pneumoconiosis cases reached CNY132 billion (USD19.34 billion), representing more than $1.1 \%$ of the total gross domestic product (GDP) (CNY11.6694 trillion (USD1.7096 trillion), in 2003) [4].

\section{Occupational poisoning}

Occupational poisoning accidents represented a large proportion (13-20\%) of occupational diseases. From 1991 to 2006 , the total number of occupational poisonings was 38,412 . The numbers of chronic and acute occupational poisonings were 16,930 and 21,482 , respectively [2]. According to the data from the Ministry of Health of The People's Republic of China (PRC) in 2007, there were 600 cases of acute chemical poisoning accounting for the thirdlargest proportion $(4.2 \%)$ of occupational diseases, while there were 1638 cases of chronic occupational poisoning $(11.26 \%)$, which followed pneumoconiosis, as the second most common occupational disease. In 2008, 309 various types of acute occupational poisoning accidents and 760 poisoning cases had been reported all over the country. The reported number of chronic poisoning cases was 1,171 in the same year. Among all the poisoning cases, the proportion of males was far more than that of females. The ratio was about 5.3:1. The total poisoning (acute and chronic poisoning) rate was $54.8 \%$ and the total mortality was $16.5 \%$. The average age at poisoning and age at death were $(31.9 \pm 9.8)$ and $(33.7 \pm 10.3)$ years, respectively [5]. Carbon monoxide, hydrogen sulfide, and ammonia were ranked as the top three causes of acute occupational poisoning, resulting in about $30 \%$ of the total cases of acute poisoning and $50 \%$ of the total deaths due to acute poisoning [3]. Hydrogen sulfide, carbon monoxide, and benzene poisoning were the three main causes of death from acute poisoning. The major acute occupational poisoning accidents were always in the chemical, manufacturing, water-treatment, mining, and construction industries. Cleaning, maintenance, manufacturing, mining, and excavation were the most dangerous posts. Lead $(\mathrm{Pb})$ and its compounds remain the leading cause of chronic poisoning $(51.83 \%)$, followed by benzene $(13.74 \%)$ and trinitrotoluene (TNT) $(11.05 \%) ; 82.97 \%$ of the cases were distributed in medium- and small-scale enterprises. Nowadays, the risk factors of occupational poisoning have been transferred rapidly from developed countries to our country, from urban to rural areas, from developed areas to less developed regions, and from the formal to the informal business sectors. Additionally, as the result of the disorderly development of township enterprises and family workshops, some enterprises did not really take on the responsibility for the 
implementation of occupational disease prevention. Meanwhile, local government supervision for occupational diseases was not in place. So occupational poisoning was found to be another threat to workers in China at present.

\section{Other occupational health problems}

Besides pneumoconiosis and occupational poisonings, musculoskeletal disorders (MSDs); psychological stress at work; occupational allergic disease; occupational tumors; and occupational nose, ear, throat, and mouth injuries were found to be common occupational diseases and workrelated diseases in China.

Special attention should also be given to the workers with high-risk factors in their jobs, such as repetitive movement and awkward work postures, which were associated with the development of MSDs. An epidemiological study in Shijiazhuang city showed that the overall prevalence of MSDs was $70.0 \%$ in nurses. Period pain and excessive mental pressure were shown to increase the risk of MSDs [odds ratios 23.8 and 10.5] [6]. The lower back was the most frequently affected body part [7]. A metaanalysis of studies of the occurrence of low back pain (LBP), the most common type of MSD, indicated that bending and twisting, static posture, vibration, and lowtemperature exposure were probably the risk factors inducing and/or exaggerating LBP.

In China, $20 \%$ of the working population was found to suffer from mental health problems [8]. Job stress, as the main psychological work-related disease in China, might lead to poor health and even injury, including cardiovascular diseases [9], MSDs [10], and mental illness [11]. A study in Chinese working women revealed that the combined exposure to job and family stress was associated with an adjusted mean $6.4 \mathrm{mmHg}$ increase in systolic blood pressure [12]. High job demands and low job control or high efforts and low rewards were found to increase the risks of job dissatisfaction, psychosomatic complaints, and depressive symptoms in a cross-sectional study at a thermal power plant in China [13].

Occupational allergic contact dermatitis (OACD) was an important medical and occupational health problem. A study of the detection of OACD by patch testing identified nickel, 4-phenylenediamine, fragrance mix, black rubber mix, colophonium, epoxy resin, and thiuram mix as the main offending allergens in OACD patients [14]. These work-related diseases should not be ignored in China.

The strategies and measures for occupational health protection

The principles of strategies and measures for occupational health protection were prevention first, then prevention and control combined; management classified (according to the severity of occupational hazards), while administration in a comprehensive way. Tertiary prevention (pathogeny prevention, occupational health surveillance, and occupational diseases treatment and healing) was regarded as the best strategy for disease control and prevention in China. Improving the process of protection, and improving healthcare were the major factors in occupational disease prevention and control measures.

\section{Laws, regulations, and standards of occupational health}

Laws, regulations, and standards were the basis of all actions. In 2002, a Code of Occupational Disease Prevention of the PRC was published and enforced. It was a great and powerful law for the prevention and control of occupational disease, and consisted of the following parts: General Provisions; Preliminary Prevention; Prevention and Control in the Course of Work; Diagnosis of Occupational Diseases and Security for Occupational Disease Patients; Supervision and Inspection; Legal Responsibility; and Supplementary Provisions. In this law, 115 diseases in ten categories were identified. The Pneumoconiosis Prevention Ordinance, industrial injury insurance regulations, a management approach to identify the diagnosis of occupational diseases and the management of occupational health checks were regulations supported by the Code of Occupational Disease Prevention of the PRC. Other laws and regulations, including the Production Safety Law of the PRC, Regulations on Labor Protection for Using Toxic Substances in the Workplace, Regulations on Protection against Radioisotopes, Regulations on Radiation-emitting Apparatus, Occupational Hazards of Confined Space Work Protection Norms, and a Public Health Emergency Ordinance were all promulgated for the prevention of occupational diseases and the protection of workers' health. So far, China has created a whole occupational health standard system, the scope of which includes physical, chemical, biological, and atmospheric conditions in the workplace. Furthermore, ergonomics factors such as labor load were included in this system. Occupational health standards in China were usually divided into mandatory national standards (GBZ) and recommended national standards (GBZ/ $\mathrm{T}$ ), including hygienic design of industrial enterprises; exposure limit of occupational hazards in the workplace; diagnosis of occupational diseases; the warning signs of occupational hazards in the workplace; and technical specifications for occupational health surveillance. In 2006, the existing occupational health standards were formulated by the Ministry of Health according to the Code of Occupational Disease Prevention of the PRC. This standards system consisted of 2 national standards, 85 national occupational health standards, and 74 industry 
occupational health standards. Meanwhile, the existing occupational disease diagnostic criteria have reached 95 items [15].

\section{Occupational health and safety research}

Enforcing occupational health and safety research was another strategy to prevent occupational hazards. For example, an eight-character acronym, which stands for "innovation (reforming technics), wet (wetting workplace), deal (enclosing source of dust), ventilation, protection (personal protection), management, education, and checking (supervise and checking)", was used to deal with dust. However, at present, there is insufficient rigorous academic research on occupational health issues in China reported in international journals. Such research, including studies of cancer mortality among textile workers in Shanghai [16], adverse effects of asbestos exposure [17], cross-shift airway responses and long-term decline in forced expiratory volume in the first second (FEV1) in cotton textile workers [18], were the most important studies about occupational lung diseases. China offered unique opportunities for occupational health research and epidemiological surveys, due to the legacy of long-term employment, stable management, and continuous exposure in the planned economy, but this advantage was slipping away during the period of economic reform.

\section{Capacities building of occupational health service and training}

An increase in the capacities building of occupational health service and training is a necessary way to protect health. For example, there was a capacity-building project aimed at shoe-manufacturing plants. The project included a 4-day training program at a 30,000-worker factory, which resulted in the establishment of health and safety committees with meaningful participation by workers in three plants [1]. However, the present capacities of occupational health services in China could not meet the demands of occupational disease prevention. In a primary center for disease control and prevention (CDC), professional and technical personnel, training, and equipment were insufficient [19]. A survey of workers' demands for an occupational health service in industrial enterprises demonstrated that half of the workers expressed dissatisfaction with the existing working conditions. The following circumstances existed to varying degrees in more than $60 \%$ of enterprises: (1) dust-proof facilities and anti-gas defenses were not installed or were damaged; and (2) personal protective equipment was not released to workers, or employees did not use protective supplies [20]. Occupational health services were limited to a small number of large enterprises. It was estimated that the coverage of occupational health services was approximately $20 \%$ [21]. Therefore, the present capacity of occupational health services needs to be further improved.

\section{Establishment and development of health supervision teams}

In order to ensure the implementation of laws, regulations, and standards, a health supervision team should be established. As early as 1954, when the nation began its industrialization, the central government had made the decision to establish a health inspection system to enforce the national health regulations and policies of industrial hygiene. Since China started its reform in the 1980s, the market-oriented economy system and rule of law has been paramount. One of the important reforms in the health sector was "health administration system reform". The main points of the reform were strengthening the safeguards of the health rights of citizens and redirecting the major functions of health authorities at various levels of government to enforce the health laws. The main tasks of health inspection in relation to occupational health included: (1) audit and approval of preventive assessments to occupational hazards and hazard severity of construction, expansion, and rebuilding of industrial premises and technical transformation and importing projects that might produce occupational hazards; (2) on-site inspection of enterprises/workplaces for implementation of the law and hazard-control measures, and environmental monitoring to ensure the concentrations or intensities of materials that cause occupational hazards in workplaces were meeting national industrial hygienic standards; (3) checking whether the pre-placement and periodic health examinations of workers exposed to occupational hazards were in compliance with national laws and regulations; (4) ensuring workers who were suffering from occupational diseases were properly treated, recuperated, and were transferred to other jobs suitable for them in line with the related regulations; and (5) supervising occupational health recordkeeping and occupational disease reporting [22].

\section{Employers' responsibilities and duties}

We have been emphasizing the employer's duty in regard to workers' health protection. Employers hold the primary responsibility for the health of their employees in workplaces and for the prevention and treatment of occupational diseases. The employer should establish an occupational health organization staffed with full-time or part-time occupational health professionals for in-plant occupational health management and service. A plan and concrete programs for hazard control should be mapped out and put into practice. Workplaces should be regularly monitored and 
evaluated for effective hazard control actions. Occupational health records (of workplace hazard monitoring and workers' health examinations) should be complete and current. And an emergency rescue plan should be carefully prepared. Workers who have been exposed to hazardous factors at workplaces should have regular health examinations. In addition, employers have the responsibility to educate their workers, such as by providing pre-placement and regular training courses to inform the workers about protection from specific occupational hazards and the need to adhere strictly to work safety rules [22].

\section{Basic occupational health services}

The implementation of basic occupational health services (BOHS) has been advocated. Recently, international organizations, such as the World Health Organization (WHO), ILO, and the International Commission on Occupational Health (ICOH), have advocated the implementation of basic health services. The functions of such services include environmental monitoring; workers' health care, safety, and health risk assessments; workplace health risk factors and risk information; and occupational diseases and work-related disease diagnosis. In China, BOHS were to prevent, control, and manage the harmful factors and harmful conditions arising from or existing in the workplace, as well as the risks endangering the health and safety of workers [23]. The service targets were smalland medium-sized industries, self-employed persons, farmers, and informal sector enterprises [24]. Because of the rapid transfer of the labor force from agricultural to nonagricultural work in rural areas and the continued migration of hazardous industries from urban to rural areas, the cover of occupational health service and control among the migrant workers was low. Therefore, BOHS for migrant workers should be strengthened. In China, national, provincial, municipal, district or county/township levels of government make up the four levels of the network for the basic framework of the BOHS system.

The occupational health network and organizations

In China, occupational health service agencies have included health supervision agencies and technical service institutions, which were composed of the four level of the network. Since China started its reform in the 1980s, a new institution, called the Institute of Health Inspection (IHI), directly affiliated with the health administrations of governments at various levels, was established. At the end of 2006, more than $90 \%$ of cities and countries had set up health inspection agencies. Each level of occupational health supervision gradually moved closer to service functions, mainly engaged in such tasks as physical examination, monitoring, and evaluation. In 2006, the Ministry of Health carried out a supervision and inspection focus on the health care situation in coal, metallurgical, pharmaceutical, building materials, electronics, and light industries (furniture manufacturing, footwear, leather processing), especially in small- and medium-sized enterprises. The following year, the health care situations of workers in coalmines and in pharmaceutical and pesticide production industries, and the health care situation of migrant workers were examined. The Institute of Occupational Health and Poisoning Control (IOHPC) under the Chinese Center for Disease Control and Prevention (CCDC) and its subordinate institutions at various levels were responsible for providing occupational health services and technical support for preventive control measures, medical surveillance, and on-the-job training [3]. Additionally, some large state-owned enterprises had their own health and safety departments, even hospitals. These agencies provided preventive and curative services, including health surveillance of workers for occupational safety and health purposes, evaluation of working capacity from the medical point of view, approval of sick leave for workers, and monitoring of environmental exposure. For medium-sized and small industrial enterprises that were not able to maintain in-plant occupational health and industrial hygiene services for their employees, the CDC at different levels could provide occupational health services. From the 1980s, hospitals for occupational disease prevention and treatment and occupational health institutions (OHIs) had rapidly been established in most provinces and some industrial sectors. To strengthen the capacity for research, training, and coordination of occupational health services, the National Center for Occupational Disease Prevention and Treatment (NCODPT) was established in the IOHPC of the CCDC [22]. The modes of the occupational health service network and organizations in China are shown in Fig. 2.

Achievements of occupational health in China

\section{Epidemiological research}

China had carried out large-scale occupational hazards monitoring, census, and epidemiological surveys, which provided a scientific basis for the development of occupational disease prevention and control policies. In February 1978, the government decided to launch and conduct a nationwide census for the toxic substances lead, benzene, mercury, phosphate pesticides, and TNT.

According to this census, the distribution of regions, industries, and types of work in the production of above substances that caused occupational poisonings in China at that time was understood. Epidemiological surveys of the 


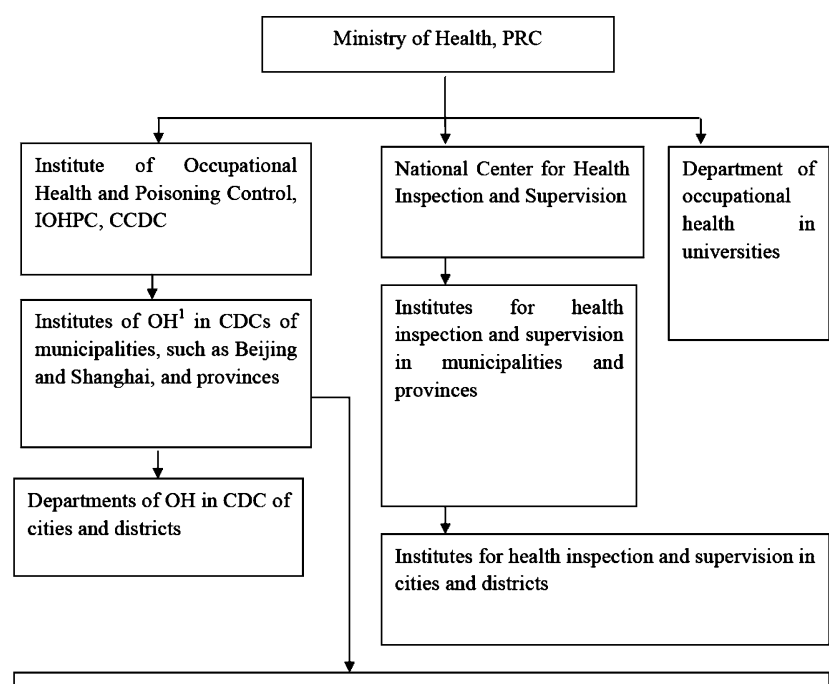

Other occupational disease prevention and control institutions, such as Prevention and Treatment Center for Occupational Disease, Departments of $\mathrm{ODs}^{2}$ at hospitals and clinics, Institute of $\mathrm{OH}$ at enterprises etc.

$1 \mathrm{OH}$ : Occupational health; 2 ODs: occupational diseases.

Fig. 2 Occupational health $(\mathrm{OH})$ network and organizations in China. PRC Peoples Republic of China, IOHPC Institute of Occupational Health and Poisoning Control, CCDC Chinese Center for Disease Control and Prevention, $C D C$ Center for disease control and prevention, $O D$ occupational disease

hazards of coke-oven complexes, chlorine ether, asbestos, benzidine, benzene, arsenic, vinyl chloride, and chromium initially identified the relationship between chemical substances used in various industries and occupational tumors. A national epidemiological survey of pneumoconiosis had found the basic status of China's incidence of pneumoconiosis. Additionally, occupational health research, such as demands for occupational health services surveys in township enterprises and so on had provided a strong scientific basis to evaluate and control occupational hazards in China correctly [25]. In 2004, investigation and analysis of occupational prevention from blood-borne pathogens in medical and health institutions in China was completed. This research led to an understanding of the current situation of the utilization of personal protective devices and problems in China's medical and health institutions. The occupational protective systems of many organizations were not feasible. It is necessary to guide the disposition, purchase, and use of personal protective devices by standard procedures in order to ensure the quality of these devices [26]. From 2001 to 2003, a cross-sectional investigation, which included 3,586 migrant workers in two districts from Beijing and Shanghai showed that $68.15 \%$ of the workers in this population were exposed to occupational risk factors, especially dust [27]. An epidemiological investigation of the incidence of occupational diseases from 1992 to 2005 in Guangxi Province indicated that pneumoconiosis and occupational poisoning were the major occupational diseases, and showed that migrant workers had become an important population who were subjected to occupational hazards [28].

\section{Occupational disease reporting system}

From the 1980s, an occupational disease reporting system had been established and improved. The general principle of this system was territorial management and hierarchical reporting. In 2003, a public health information system was established in China. This was a new opportunity for the improvement of the occupational disease reporting system. On June 1, 2006, a relatively perfect national network of occupational disease reporting had been started and was being used formally. In this new system, occupational disease was reported directly to IOHPC through the network. The system is characterized by the following points: (1) standardization of reporting indicators: the data are more readily available and comparable; (2) the amounts of data from cases of occupational disease have been increased by the use of identification cards and affiliation information; (3) the real-time data about the number of cases of pneumoconiosis and prevalence trends can be obtained; (4) the system enabled dynamic observation and follow-up reports of the cases; (5) the reporting units for monitoring the health of workers and detection of workplace hazards have been changed from area units to employment units, including agency codes, economic types, and size [29]. Occupational disease reporting has been an important part of China's public health information system.

\section{Pilot study of basic occupational health services}

In the regions in which migrant workers were localized, such as Beijing, Chongqing, Guangdong, Guangxi, Anhui, and Guizhou, China had developed a 3-year pilot study of BOHS in 2006. The goals of this pilot study were to survey the basic situation of occupational health services in pilot units; to promote the capacity of occupational health service building and training in the CDC of each district; to do personnel training; to formulate occupational health work plans, and to develop pilot work assessments. The pilot work has been basically successful. Other projects, such as intervention projects for occupational health promotion in 1998 and intervention projects for occupational hazards in small- and medium-sized enterprises in 2005, were intervention projects carried out by the Ministry of Health and WHO as the goals of BOHS. Since 2002, the last week of April every year has been marked as Awareness Week for the Code of Occupational Disease Prevention of the PRC. After several years of publicity and education, the legal 
awareness of occupational disease prevention and control shown by all levels of government, and by employers and workers has been significantly increased. In addition, the occupational health supervision departments have gradually carried out their service functions. For example, after the implementation of the Code of Occupational Disease Prevention of the PRC, the total number of enterprises under supervision and the number of rectification cases ordered were greatly increased in Beijing [30]. Another survey showed that the quality of occupational health supervision work had been improved every year from 1998 to 2004 [31].

The challenges and problems for occupational health in China

The work of occupational disease prevention and control still faces challenges. First of all, the number of people in China exposed to occupational hazards and the number of occupational disease cases was found to be large. Secondly, the distribution of occupational hazards in industry was widespread and the hazards in small- and mediumsized enterprises were even more serious. Occupational hazards existed in varying degrees in traditional industries, such as coal, metallurgy, chemical, and construction, and in emerging modern industries, including the car manufacturing, pharmaceutical, computer, and bioengineering industries. A report of a sample survey in 30 counties in 1990 showed that $82.69 \%$ of rural industrial enterprises had at least one type of occupational hazard in their work environment. Workers employed in at least one type of hazardous working environment accounted for $33.91 \%$ of blue-collar workers [32]. Thirdly, the transfer of occupational hazards and the mobility of migrant workers have made the work of occupational prevention and treatment more difficult. With the introduction of funds and new technologies, a number of occupational hazards from overseas enterprises and technologies have been transferred from other countries to China. At the same time, domestically, occupational hazards have been transferred from cities and industrial areas to rural areas, from economically developed regions to less developed regions, and from large- and medium-sized enterprises to small- and medium-sized enterprises. The agricultural labor force in China is about 200 million, most of them involved in toxic and hazardous operations. Because of the mobility and the complex situation of exposure to hazards, it is hard to estimate the health effects in the migrant workers. Finally, the characteristics of occupational disease were often so latent and delayed that the effects were often ignored. As an example, in pneumoconiosis, the incubation period can be as long as several years or even more than a decade. In addition, previously, the tasks of the occupational health system, which involves a number of departments and a cooperative working mechanism, had not yet been fully established. The lack of government investment in disease prevention capacity lags behind the investment in economic development. Furthermore, the data on occupational hazards detection in workplaces did not reflect the actual situation. The effects of new work-related diseases, such as musculoskeletal diseases, occupational mental illness caused by job stress, and occupational allergic diseases have gradually increased. Governments and enterprises should pay sufficient attention to these new hazards in order to prevent new occupational diseases and protect the health of workers. From 1990 to 2005, the lead exposure levels at most workplaces in China exceeded the occupational exposed limit for hazardous agents. The overall occupational health monitoring system needs to be built up powerfully, especially in some areas where these systems were underdeveloped [33]. In 2000, it was reported that the routine occupational health service coverage provided for township enterprises was only $1.4-36 \%$ [32]. Therefore, the quality and coverage of occupational health services also needs to be improved with great strides.

\section{Perspectives}

Now China has carried out a series of steps to reduce the incidence of occupational disease. However, it cannot meet the demand for efficient prevention and control. To continue the development of occupational health in China, we will need to strengthen the supervision and management of workers, especially in some representative industries with high risks, such as coalmines, the pharmaceutical industry, and pesticide manufacturers. We will also need to promote research on the prevention and control of occupational health; motivate the government to improve regulations and standards; perfect the diagnosis of occupational diseases and improve the reporting system; as well as train health professionals. Furthermore, new occupational risks, such as ergonomic factors and job stress, as well as the traditional hazards, will need attention simultaneously.

\section{References}

1. Brown GD, O'Rourke D. The race to China and implications for global labor standards. Int J Occup Environ Health. 2003;9:299_ 301.

2. Ji F, Xia ZL. China's occupational poisoning hazards and highrisk toxic workplace management (in Chinese). Ind Med. 2008;6:404-6.

3. Liang YX, Xiang QY. Occupational health services in PR China. Toxicology. 2004;198:45-54. 
4. Chen L. It's urgent to prevent occupational diseases-written after the "Code of Occupational Disease Prevention of PRC" was implemented three years (in Chinese). Mod Occup Saf. 2005;5:28-9.

5. Zhang M, Li T, Wang HQ, Wang HF, Chen SY, Du XY, et al. Characterization of severe acute occupational poisoning accidents in China between 1998 and 2003 (in Chinese). Chin J Ind Hyg Occup Dis. 2006;24:707-11.

6. Smith DR, Wei N, Kang L, Wang RS. Musculoskeletal disorders among professional nurses in mainland China. J Prof Nurs. 2004;20:390-5.

7. Shiue HS, Lu CW, Chen CJ, Shih TS, Wu SC, Yang CY, et al. Musculoskeletal disorder among 52,261 Chinese restaurant cooks cohort: result from the National Health Insurance Data. J Occup Health. 2008;50:163-8.

8. Fan XY. Epidemiological study of job stress (to be continued) (in Chinese). Occup Health Emerg Rescue. 2004;1:53.

9. Dimsdale JE. Psychological stress and cardiovascular disease. J Am Coll Cardiol. 2008;51:1237-46.

10. Chen JC, Chang WR, Chang W, Christiani D. Occupational factors associated with low back pain in urban taxi drivers. Occup Med (Lond). 2005;55:535-40.

11. Eum KD, Li J, Lee HE, Kim SS, Paek D, Siegrist J, et al. Psychometric properties of the Korean version of the effort-reward imbalance questionnaire: a study in a petrochemical company. Int Arch Occup Environ Health. 2007;80:653-61.

12. Xu L, Siegrist J, Cao W, Li L, Tomlinson B, Chan J. Measuring job stress and family stress in Chinese working women: a validation study focusing on blood pressure and psychosomatic symptoms. Women Health. 2004;39:31-46.

13. Yu S, Gu G, Zhou W, Wang S. Psychosocial work environment and well-being: a cross-sectional study at a thermal power plant in China. J Occup Health. 2008;50:155-62.

14. Li LF, Sujan SA, Wang J. Detection of occupational allergic contact dermatitis by patch testing. Contact Dermatitis. 2003;49:189-93.

15. Health Policy and Regulation Department in Ministry of Health, Center for Health Supervision in Ministry of Health. Occupational health standards, occupational disease diagnostic criteria (in Chinese). China Health Law. 2006;3:4.

16. Fang SC, Eisen EA, Dai H, Zhang H, Hang J, Wang X, et al. Cancer mortality among textile workers in Shanghai, China: a preliminary study. J Occup Environ Med. 2006;48:955-8.

17. Wang X, Yano E, Wang Z, Wang M, Christiani DC. Adverse effects of asbestos exposure and smoking on lung function. Am J Ind Med. 2006;49:337-42.

18. Wang X, Zhang HX, Sun BX, Dai HL, Hang JQ, Eisen E, et al. Cross-shift airway responses and long-term decline in FEV1 in cotton textile workers. Am J Respir Crit Care Med. 2008;177:316-20.

19. $\mathrm{Lu} \mathrm{Y}, \mathrm{Lu} \mathrm{XQ}$. Status and recommendations of occupational health services in primary CDC (in Chinese). Chin J Pest Control. 2007;1:60-1.

20. Sui SF, Li SX, Kong Fl, Wang Y. Surveying the workers' demand of occupational health service in industrial enterprise (in Chinese). Chin Health Serv Manag. 2008;7:494-6.

21. Li DH. Basic occupational health service for all the workforce (in Chinese). Chin J Ind Hyg Occup Dis. 2005;5:321-2.

22. Su Z. Occupational health and safety legislation and implementation in China. Int J Occup Environ Health. 2003;9:302-8.

23. Rantanen J, Du XY, Wang D, Li WJ, Zhang M, Li T. Primary occupational hygiene service-risk evaluation (in Chinese). Chin J Ind Hyg Occup Dis. 2009;27:108-10.

24. Yu WL, Liang YX. BOHS mode: necessity for guaranteeing occupational health of migrant workers (in Chinese). Chin J Ind Hyg Occup Dis. 2008;26:676-8.

25. Song WZ, Su Z, Liu SJ. To meet a new upsurge of occupational diseases prevention and control in China in twenty-first century (in Chinese). Chin J Ind Hyg Occup Dis. 2001;5:321-2.

26. Wang HQ, Zhang M, LJ T, Guo YH, Zhang L, Cao XJ, et al. Investigation and analysis on occupational prevention from the blood-borne pathogens in medical and health institutions in China (in Chinese). Chin J Ind Hyg Occup Dis. 2006;32:18-23.

27. Li CL, Fan XE, Li S, Wang JP, Liu HL. The situation of migrant workers occupational health survey in industrial enterprises (in Chinese). Chin J Ind Hyg Occup Dis. 2007;25:749-51.

28. Li YQ, Ge XM, Li H, Wang CY, Wang HY, Huang CY, et al. An epidemiological investigation about the incidence of occupational diseases from 1992 to 2005 in Guangxi province (in Chinese). Chin J Ind Hyg Occup Dis. 2007;25:741-4.

29. Chen SY, Wang D, Zhang M. Report of occupational diseases in internet era (in Chinese). Chin J Ind Hyg Occup Dis. 2008;11:673-5.

30. Tang DM, Lv JH. Analysis of occupational health supervision from 2001 to 2002 in Beijing (in Chinese). Occup Health. 2005;11:1708-9.

31. Zhang Y. Quality evaluation of occupational health supervision by Topsis method (in Chinese). Chin J Ind Med. 2006;13:191-2.

32. Zhi S, Sheng W, Levine SP. National occupational health service policies and programs for workers in small-scale industries in China. AIHAJ. 2000;61:842-9.

33. Ye X, Wong O. Lead exposure, lead poisoning, and lead regulatory standards in China, 1990-2005. Regul Toxicol Pharmacol. 2006;46:157-62. 